\title{
Utilization of Early Invasive Management Strategies for High-Risk Patients With Non-ST-Segment Elevation Acute Coronary Syndromes Results From the CRUSADE Quality Improvement Initiative
}

\begin{tabular}{l}
\hline Deepak L. Bhatt, MD \\
\hline Matthew T. Roe, MD, MHS \\
\hline Eric D. Peterson, MD, MPH \\
\hline Yun Li, MS \\
\hline Anita Y. Chen, MS \\
\hline Robert A. Harrington, MD \\
\hline Adam B. Greenbaum, MD \\
\hline Peter B. Berger, MD \\
\hline Christopher P. Cannon, MD \\
\hline David J. Cohen, MD, MSc \\
\hline C. Michael Gibson, MS, MD \\
\hline Jorge F. Saucedo, MD \\
\hline Neal S. Kleiman, MD \\
\hline Judith S. Hochman, MD \\
\hline William E. Boden, MD \\
\hline Ralph G. Brindis, MD, MPH \\
\hline W. Frank Peacock, MD \\
\hline Sidney C. Smith, Jr, MD \\
\hline Charles V. Pollack, Jr, MD \\
\hline W. Brian Gibler, MD \\
\hline E. Magnus Ohman, MD \\
\hline for the CRUSADE Investigators \\
\hline
\end{tabular}

$\mathrm{N}$ THE PAST DECADE, SEVERAL ADvances have occurred in the management of non-ST-segment elevation acute coronary syndromes (NSTE ACS). Pharmacotherapies, such as intravenous platelet glycoprotein (Gp) IIb/IIIa inhibitors, low-molecularweight heparin, and clopidogrel, have demonstrated incremental benefits for patients with NSTE ACS. ${ }^{1-4}$ Complemen-

Context The American College of Cardiology/American Heart Association (ACC/ $\mathrm{AHA}$ ) guidelines for the management of non-ST-segment elevation acute coronary syndromes (NSTE ACS) recommend early invasive management for high-risk patients, given the benefits with this approach demonstrated in randomized clinical trials.

Objectives To determine the use and predictors of early invasive management strategies (cardiac catheterization $<48$ hours following presentation) in high-risk patients with NSTE ACS and to examine the association of early invasive management with mortality.

Design, Setting, and Patients The CRUSADE (Can Rapid Risk Stratification of Unstable Angina Patients Suppress Adverse Outcomes With Early Implementation of the ACC/AHA Guidelines) Quality Improvement Initiative evaluated care patterns and outcomes for 17926 high-risk NSTE ACS patients (positive cardiac markers and/or ischemic electrocardiographic changes) based on ACC/AHA guidelines recommendations at 248 US hospitals with catheterization and revascularization facilities between March 2000 and September 2002.

Main Outcome Measures Use of early invasive management within 48 hours of presentation, predictors of early invasive management, and in-hospital mortality.

Results Of the 17926 patients analyzed, 8037 (44.8\%) underwent early cardiac catheterization less than 48 hours following presentation. Predictors of early invasive management included cardiology care, younger age, lack of prior or current congestive heart failure, lack of renal insufficiency, ischemic electrocardiographic changes, positive cardiac markers, white race, and male sex. Patients treated with early invasive management were more likely to be treated with medications and interventions recommended by the ACC/AHA guidelines and had a lower risk of in-hospital mortality after adjusting for differences in clinical characteristics and after comparing propensitymatched pairs $(2.5 \%$ vs $3.7 \%, P<.001)$.

Conclusions An early invasive management strategy is not utilized in the majority of high-risk patients with NSTE ACS. This strategy appears to be reserved for patients without significant comorbidities and those cared for by cardiologists and is associated with a lower risk of in-hospital mortality.

Author Affiliations: Cleveland Clinic Foundation, Cleveland, Ohio (Drs Bhatt and Peacock); Duke Clinical Research Institute, Durham, NC (Drs Roe, Peterson, Harrington, and Berger and Mss Li and Chen), Henry Ford Heart and Vascular Institute, Detroit, Mich (Dr Greenbaum); Brigham and Women's Hospital, Boston, Mass (Dr Cannon); Beth Israel Deaconess Medical Center, Boston, Mass (DrCohen); TIMI Study Group, Harvard Medical School, Boston, Mass (Dr Gibson); University of Oklahoma Health Sciences Center, Oklahoma City (Dr Saucedo); Baylor College of Medicine, Houston, Tex (Dr Kleiman); New York University School of Medicine, New
York, NY (Dr Hochman); University of Connecticut, Hartford (Dr Boden); Kaiser Permanente Health System, San Francisco, Calif (Dr Brindis); University of North Carolina at Chapel Hill (Drs Smith and Ohman); Pennsylvania Hospital, Philadelphia (Dr Pollack); and University of Cincinnati, Cincinnati, Ohio (Dr Gibler).

For a complete list of the CRUSADE Investigators, see www.jama.com.

Corresponding Author: Deepak L. Bhatt, MD, Cleveland Clinic Foundation, Department of Cardiovascular Medicine/Desk F25, 9500 Euclid Ave, Cleveland, OH 44195 (bhattd@ccf.org). 
tary to advances in antithrombotic and antiplatelet therapies, catheterizationbased strategies for revascularization have also improved. ${ }^{5}$ Randomized clinical trial data collectively support the use of an early invasive approach with prompt cardiac catheterization compared with an initial conservative approach that reserves cardiac catheterization for patients who develop recurrent ischemia despite medical therapy. ${ }^{6,7}$ The Treat Angina with Aggrastat and Determine Cost of Therapy with an Invasive or Conservative Strategy (TACTICS)-Thrombolysis in Myocardial Infarction (TIMI)-18 trial found that catheterization within the first 48 hours after presentation was superior to an initial strategy of medical management, particularly in high-risk patients with elevated troponin levels or ST-segment depression. ${ }^{6}$ Similarly, The Fast Revascularization during Instability in Coronary artery disease (FRISC II) trial demonstrated a significant reduction in long-term mortality with early invasive management for NSTE ACS. ${ }^{8}$

Professional practice guidelines have rapidly incorporated advances in the treatment of NSTE ACS. ${ }^{9,10}$ However, there is a time lag between clinical trial advances, revision of guidelines, dissemination of recommendations to practicing physicians, and integration into clinical practice. ${ }^{11}$ Therefore, we sought to characterize the contemporary utilization of early invasive management strategies and determine the relationship between early invasive management and mortality in a group of highrisk NSTE patients included in the CRUSADE (Can Rapid Risk Stratification of Unstable Angina Patients Suppress Adverse Outcomes With Early Implementation of the ACC/AHA [American College of Cardiology/ American Heart Association] Guidelines) Quality Improvement Initiative.

\section{METHODS \\ Patients, Inclusion Criteria, and Data Collection}

Patients included in the ongoing CRUSADE Quality Improvement Initiative have ischemic symptoms at rest within 24 hours prior to presentation and high- risk features including ST-segment depression, transient ST-segment elevation, or positive cardiac markers (elevated troponin I or T and/or creatine kinase-MB $>$ upper limit of normal for participating institutions). ${ }^{12}$

Data were collected only during the hospitalization in an anonymous fashion without informed consent after the institutional review board of each institution approved participation in this quality improvement initiative. Data collected included baseline clinical characteristics, use of acute medications (within 24 hours of hospital arrival), use and timing of invasive cardiac procedures, laboratory results, in-hospital clinical outcomes, and discharge therapies and interventions. Decisions regarding the use of invasive procedures were made by the treating physicians. Contraindications to specific therapies given Class IA or IB recommendations by the ACC/AHA guidelines were recorded. ${ }^{9,13}$ Data collectors at each participating site classified patients according to race and/or ethnicity based on chart abstraction using standard definitions that were provided. These data were collected as part of baseline demographic information to see if there were differences in care based on race/ethnicity.

\section{Analysis Cohort}

To account for the expected delays in timing of diagnostic cardiac catheterization, percutaneous coronary intervention (PCI), and coronary artery bypass grafting (CABG) for patients presenting to institutions without full revascularization capabilities, patients presenting to hospitals without angioplasty or surgical facilities were excluded from the analysis. Furthermore, we excluded patients who were transferred in from other institutions or transferred out from the initial presenting institution since complete presenting characteristics, acute treatments, clinical outcomes, and use and timing of invasive procedures were not available for these patients. Thus, the final analysis cohort comprised patients who presented directly to hospitals with catheterization laborato- ries and angioplasty or cardiac surgical capabilities.

\section{Statistical Analysis}

Baseline characteristics and hospital features were compared among patients who did or did not receive early invasive management (cardiac catheterization within 48 hours of hospital presentation per the ACC/AHA guidelines recommendations). Medians with 25th and 75th percentiles were reported for continuous variables and frequencies for categorical variables. $\chi^{2}$ Tests were used for categorical variables, and Wilcoxon rank-sum tests were used to compare continuous variables.

To determine the factors that predict the likelihood of early invasive management, a multiple logistic regression model was developed using the stepwise approach. The predictive ability of this model was summarized using a C-index.

Since CRUSADE is an observational study, patients were not randomized by treatment. In comparing patients who underwent early catheterization to those who did not undergo early catheterization with respect to in-hospital outcomes (eg, postadmission infarction, cardiogenic shock, congestive heart failure [CHF], red blood cell transfusion, death, and the composite outcome of postadmission infarction or death), we adjusted for baseline patient clinical risk factors including age, sex, body mass index, race, family history of coronary artery disease, hypertension, diabetes, smoking status, hypercholesterolemia, prior MI, prior $\mathrm{PCI}$, prior $\mathrm{CABG}$, prior CHF, prior stroke, renal insufficiency, ST-segment depression, transient STsegment elevation, positive cardiac markers, signs of CHF, heart rate, systolic blood pressure, and insurance status as well as for provider and hospital characteristics (physician specialty, total number of hospital beds, region of the country, PCI or CABG capabilities, and type of hospital [academic or nonacademic]) and hours of presentation. For these analyses, generalized estimating equation (GEE) models were used to adjust for correlations among clustered re- 
sponses (eg, within-hospital correlations) since patients within a single Furthermore, since patients who died within 48 hours would not have the chance to receive early catheterization, hospital are more likely to be similar. ${ }^{14}$

we performed sensitivity analyses to investigate the relationship between early catheterization and in-hospital mortality after excluding early deaths within 24 to 48 hours. We also performed subgroup analyses to explore further the as-

\begin{tabular}{|c|c|c|c|}
\hline Characteristic & $\begin{array}{c}\text { No Early } \\
\text { Invasive Care } \\
(n=9889)\end{array}$ & $\begin{array}{c}\text { Early } \\
\text { Invasive Care } \\
(n=8037)\end{array}$ & $\begin{array}{c}P \\
\text { Value } \\
\end{array}$ \\
\hline \multicolumn{4}{|l|}{ Demographics } \\
\hline Age, median (IQR), y & $73(60-81)$ & 63 (53-73) & $<.001$ \\
\hline Female sex & $4511(45.6)$ & $2842(35.4)$ & $<.001$ \\
\hline BMI, median (IQR) & $27.3(24-30.3)$ & $28.1(25.2-32)$ & $<.001$ \\
\hline White race & $7446(75.3)$ & $6521(81.1)$ & $<.001$ \\
\hline \multicolumn{4}{|l|}{ Insurance status } \\
\hline HMO/private & $3834(38.8)$ & $4181(52.0)$ & $<.001$ \\
\hline Medicaid/Medicare & $5437(55.0)$ & 3120 (38.8) & $<.001$ \\
\hline Self/none & $618(6.3)$ & $736(9.2)$ & $<.001$ \\
\hline \multicolumn{4}{|l|}{ Risk factors } \\
\hline Family history of CAD & 3096 (31.3) & $3376(42.0)$ & $<.001$ \\
\hline Hypertension & $7120(72.0)$ & $5283(65.7)$ & $<.001$ \\
\hline Diabetes mellitus & $3641(36.8)$ & $2229(27.7)$ & $<.001$ \\
\hline Current/recent smoker & $2157(21.8)$ & $2591(32.2)$ & $<.001$ \\
\hline Hypercholesterolemia & $4259(43.1)$ & $4026(50.1)$ & $<.001$ \\
\hline \multicolumn{4}{|l|}{ Medical history } \\
\hline Prior myocardial infarction & $3429(34.7)$ & $2178(27.1)$ & $<.001$ \\
\hline Prior PCl & $2046(20.7)$ & $2095(26.1)$ & $<.001$ \\
\hline Prior CABG & $2289(23.2)$ & $1518(18.9)$ & $<.001$ \\
\hline Prior CHF & $2780(28.1)$ & $684(8.5)$ & $<.001$ \\
\hline Prior stroke & $1419(14.3)$ & $518(6.4)$ & $<.001$ \\
\hline Renal insufficiency $†$ & $1945(19.7)$ & $530(6.6)$ & $<.001$ \\
\hline \multicolumn{4}{|l|}{ Presenting characteristics } \\
\hline Heart rate, median (IQR), beats/min & $86(72-102)$ & $80(68-94)$ & $<.001$ \\
\hline SBP, median (IQR), mm Hg & $145(125-166)$ & $148(130-168)$ & $<.001$ \\
\hline ST depression & $4098(41.4)$ & $3490(43.4)$ & .008 \\
\hline Transient ST elevation & $780(7.9)$ & $1041(13.0)$ & $<.001$ \\
\hline Positive cardiac markers & $8391(84.9)$ & $6855(85.3)$ & .41 \\
\hline $\mathrm{CHF}$ at presentation & $2983(30.2)$ & $977(12.2)$ & $<.001$ \\
\hline \multicolumn{4}{|l|}{ Hospital characteristics } \\
\hline CABG facility & $9251(93.5)$ & $7755(96.5)$ & $<.001$ \\
\hline Hospital beds, median (IQR), No. & $428(291-554)$ & $419(288-545)$ & $<.001$ \\
\hline COTH hospital & $3579(36.2)$ & $2390(29.7)$ & $<.001$ \\
\hline \multicolumn{4}{|l|}{ Region } \\
\hline Northeast & 2092 (21.2) & $1236(15.4)]$ & \multirow{4}{*}{$<.001$} \\
\hline South & $3347(33.8)$ & $2882(35.8)$ & \\
\hline West & $983(9.9)$ & $808(10.1)$ & \\
\hline Midwest & $3467(35.1)$ & $3111(38.7)$ & \\
\hline Cardiology careł & $4468(45.2)$ & $5577(69.4)$ & $<.001$ \\
\hline Off-hours presentation§ & $5819(58.8)$ & $4319(53.7)$ & $<.001$ \\
\hline \multicolumn{4}{|c|}{$\begin{array}{l}\text { Abbreviations: BMl, body mass index, calculated as weight in kilograms divided by the square of height in meters; } \\
\text { CABG, coronary artery bypass graft; CAD, coronary artery disease; CHF, congestive heart failure; COTH, Council of } \\
\text { Teaching Hospitals; HMO, health maintenance organization; IQR, interquartile range; PCl, percutaneous coronary } \\
\text { intervention; SBP, systolic blood pressure. } \\
\text { *Data are presented as number and percentage unless otherwise indicated. Clinical characteristics and medical his- } \\
\text { tory were obtained from chart abstraction. } \\
\text { †Defined as creatinine level greater than } 2.0 \mathrm{mg} / \mathrm{dL}(176.8 \mu \mathrm{mol} / \mathrm{L}) \text {, calculated creatinine clearance less than } 30 \mathrm{~mL} / \\
\text { min }(0.5 \mathrm{~mL} / \mathrm{s}) \text {, or need for chronic renal dialysis. } \\
\text { †Admitted to a primary cardiology service. } \\
\text { \$Presentation from } 5 \text { PM to } 7 \text { AM on weekdays and anytime on weekends. }\end{array}$} \\
\hline
\end{tabular}

sociation between early catheterization and in-hospital mortality across different subgroups.

The Platelet glycoprotein IIb/IIIa in Unstable angina: Receptor Suppression Using Integrilin (eptifibatide) Therapy (PURSUIT) 30-day mortality risk model for NSTE ACS was modified for this analysis to predict the risk of inhospital mortality in the original PURSUIT population from presenting clinical characteristics. ${ }^{15}$ The original PURSUIT population was divided into equal tertiles based on the adjusted risk of in-hospital mortality. The tertiles of patients were then categorized as lowrisk, moderate-risk, and high-risk. The modified PURSUIT model was then applied to the CRUSADE population, which was divided into risk groups based on the predicted in-hospital mortality rate calculated for each patient from presenting clinical characteristics. The association between early catheterization and unadjusted in-hospital mortality was examined within each risk group to characterize further the impact of early catheterization among patients with similar baseline risk features.

As an additional way of accounting for nonrandom treatment assignment, we adjusted for factors favoring selection of one treatment over another using propensity scores. ${ }^{16}$ Using multivariable GEE, a propensity score model was created to estimate the likelihood of early catheterization. Greedy matching techniques were used to match each patient with another patient of similar propensity score of receiving early catheterization. ${ }^{17}$ The Pearson $\chi^{2}$ test was used to compare mortality rates for these matched pairs between patients who did and did not undergo early catheterization.

A $P$ value of $<.05$ was established as the level of statistical significance for all tests. All analyses were performed using SAS software (version 8.2, SAS Institute, Cary, NC).

\section{RESULTS}

\section{Patients}

The population for this analysis consisted of 30295 patients with high- 
risk NSTE ACS who were treated at 248 US hospitals between March 1, 2000, and September 30, 2002. After we excluded 8816 patients who were either transferred in from other hospitals or transferred out from the presenting institution, a total of 21479 patients were left. Among these patients, 185 did not have information on hospital surgical capabilities, 1140 were admitted to hospitals without catheterization capabilities, and 2228 were admitted to hospitals without PCI or CABG capabilities. After excluding these patients, 17926 were included in the final analysis population who presented to 248 US hospitals with diagnostic cardiac catheterization facilities and capabilities for PCI or CABG or both.

\section{Use of Invasive Procedures}

Among the 17926 patients included in this analysis, 11153 (62.2\%) underwent cardiac catheterization at some point during their hospitalization, 8037 (44.8\%) underwent early invasive management (cardiac catheterization within 48 hours of presentation), and 3116 (17.4\%) underwent cardiac catheterization more than 48 hours following presentation. Of the 8037 patients who underwent early invasive management, 75\% were revascularized: 4733 (58.9\%) underwent PCI and 1296 (16.1\%) underwent CABG. There was a large variation in the use of early invasive management at the 248 hospitals included in this analysis as the median use of early catheterization was $47.8 \%$, but the interquartile range was 33.3\% to $57.6 \%$. Temporal analyses demonstrated a slight upward trend in the use of early invasive management from the third quarter of 2001 until the third quarter of 2002 (46.8\%, 41.2\%, 43.4\%, $44.4 \%$, and $48.6 \%$, respectively).

\section{Clinical Characteristics and Predictors of \\ Early Invasive Management}

Patients who underwent early catheterization were younger, more often male and white, more likely to be admitted to a cardiology service, and less likely to have CHF or renal insufficiency
(TABLE 1). The strongest independent predictors of early invasive management included cardiology care, younger age, lack of renal insufficiency, lack of prior $\mathrm{CHF}$, slower presenting heart rate, and lack of signs of CHF on presentation (TABLE 2). The C-index for the predictive model was 0.761 .

\section{Care Patterns}

Patients who underwent early invasive management were more likely to receive ACC/AHA guidelinesrecommended acute and discharge medications and interventions com- pared with patients who did not undergo early invasive management (Table 3, Table 4).

\section{Clinical Outcomes}

The unadjusted incidence of inhospital mortality was $2.0 \%$ for patients who underwent early invasive management within 48 hours compared with $6.2 \%$ for patients who did not undergo early invasive management. The unadjusted frequencies of other adverse outcomes were lower in patients who underwent early invasive management (TABLE 5). The adjusted risks of

\begin{tabular}{|c|c|c|c|}
\hline Variable & $\chi^{2}$ & Odds Ratio (95\% Cl) & $P$ Value \\
\hline Cardiology care & 513.5 & $2.21(2.06-2.37)$ & $<.001$ \\
\hline Age (per 10 y)† & 218.0 & $0.80(0.77-0.82)$ & $<.001$ \\
\hline Prior CHF & 176.8 & $0.49(0.44-0.55)$ & $<.001$ \\
\hline Renal insufficiency $\ddagger$ & 132.6 & $0.51(0.46-0.58)$ & $<.001$ \\
\hline Presenting heart rate (per 10/min)† & 102.3 & $0.92(0.91-0.93)$ & $<.001$ \\
\hline $\mathrm{CHF}$ at presentation & 77.9 & $0.66(0.60-0.72)$ & $<.001$ \\
\hline Transient ST elevation & 71.0 & $1.61(1.43-1.81)$ & \multirow{2}{*}{$<.001$} \\
\hline ST depression & & $1.26(1.16-1.36)$ & \\
\hline Positive cardiac markers & 60.6 & $1.51(1.36-1.67)$ & $<.001$ \\
\hline White race & 48.5 & $1.36(1.25-1.48)$ & $<.001$ \\
\hline Prior PCl & 48.3 & $1.35(1.24-1.47)$ & $<.001$ \\
\hline CABG capabilities & 46.5 & $1.68(1.43-1.98) 7$ & \multirow{2}{*}{$<.001$} \\
\hline Hospital angioplasty capabilities & & $1.41(1.12-1.76)$ & \\
\hline Off-hours presentation§ & 44.6 & $0.80(0.75-0.85)$ & $<.001$ \\
\hline Prior stroke & 42.7 & $0.68(0.60-0.72)$ & $<.001$ \\
\hline Presenting SBP (per 10 mm Hg)† & 37.6 & $1.03(1.02-1.04)$ & $<.001$ \\
\hline Northeast (vs South) region & 34.3 & $0.82(0.74-0.91) 7$ & \multirow{3}{*}{$<.001$} \\
\hline Midwest (vs South) region & & $1.10(1.02-1.19)$ & \\
\hline West (vs South) region & & $1.07(0.95-1.21)$ & \\
\hline Prior Ml & 33.8 & $0.79(0.73-0.85)$ & $<.001$ \\
\hline Hypercholesterolemia & 28.1 & $1.21(1.13-1.29)$ & $<.001$ \\
\hline COTH hospital & 25.7 & $0.80(0.74-0.87)$ & $<.001$ \\
\hline Female sex & 17.9 & $0.86(0.80-0.92)$ & $<.001$ \\
\hline Prior CABG & 17.5 & $0.83(0.76-0.91)$ & $<.001$ \\
\hline Family history of CAD & 15.3 & $1.15(1.07-1.24)$ & $<.001$ \\
\hline BMI (per 5 units) & 14.1 & $1.05(1.03-1.08)$ & $<.001$ \\
\hline Hospital beds (per 100)† & 13.7 & $0.96(0.95-0.98)$ & $<.001$ \\
\hline Medicare/Medicaid vs HMO/private insurance & 10.6 & $0.89(0.82-0.96)$ & \multirow{2}{*}{$<.001$} \\
\hline Self/none vs HMO/private insurance & & $0.92(0.81-1.05)$ & \\
\hline Current/recent smoking & 4.2 & $1.09(1.00-1.18)$ & .04 \\
\hline Diabetes mellitus & 4.1 & $0.93(0.86-1.00)$ & .04 \\
\hline \multicolumn{4}{|c|}{$\begin{array}{l}\text { Abbreviations: BMl, body mass index, calculated as weight in kilograms divided by the square of height in meters; } \\
\text { CABG, coronary artery bypass graft; CAD, coronary artery disease; CHF, congestive heart failure; Cl, confidence } \\
\text { interval; COTH, Council of Teaching Hospitals; Ml, myocardial infarction; PCl, percutaneous coronary intervention; } \\
\text { SBP, systolic blood pressure. } \\
\text { *Model C-index }=0.761 \text {. } \\
\text { †Continuous variables. } \\
\text { fDefined as creatinine level greater than } 2.0 \mathrm{mg} / \mathrm{dL}(176.8 \mu \mathrm{mol} / \mathrm{L}) \text {, calculated creatinine clearance less than } 30 \\
\mathrm{~mL} / \mathrm{min}(0.5 \mathrm{~mL} / \mathrm{s}) \text {, or need for chronic renal dialysis. } \\
\S \text { Presentation to hospital between } 5 \mathrm{PM} \text { to } 7 \mathrm{AM} \text { during weekdays or anytime during weekends. }\end{array}$} \\
\hline
\end{tabular}


death and death or MI were lower in patients who underwent early invasive management, whereas the adjusted risks of cardiogenic shock and red blood cell

Table 3. Acute Care ( $<24$ Hours) Patterns by Early Invasive Management*

\begin{tabular}{lcc}
\hline & $\begin{array}{c}\text { No Early } \\
\text { Invasive Care, \% } \\
\text { ( } \mathbf{n = 9 8 8 9 )}\end{array}$ & $\begin{array}{c}\text { Early Invasive } \\
\text { Care, \% } \\
\text { ( } \mathbf{n = 8 0 3 7 )}\end{array}$ \\
\hline Aspirin & 87.7 & 93.8 \\
Clopidogrel & 26.1 & 51.3 \\
$\begin{array}{l}\text { 3-Blocker } \\
\text { Any heparin }\end{array}$ & 71.9 & 77.7 \\
$\begin{array}{l}\text { Unfractionated } \\
\text { heparin }\end{array}$ & 73.7 & 88.8 \\
LMW heparin & 32.4 & 63.3 \\
Gp llb/lla & 14.0 & 32.7 \\
inhibitor & 14.2 & 50.9 \\
\hline
\end{tabular}

Abbreviations: Gp, glycoprotein; LMW, low-molecularweight.

"Among patients without listed contraindications. All $P$ values $<.001$.

Table 4. Discharge Care Patterns by Early Invasive Management*

\begin{tabular}{|c|c|c|}
\hline & $\begin{array}{c}\text { No Early } \\
\text { Invasive } \\
\text { Care, \% } \\
(\mathrm{n}=9889)\end{array}$ & $\begin{array}{c}\text { Early } \\
\text { Invasive } \\
\text { Care, \% } \\
(\mathrm{n}=8037)\end{array}$ \\
\hline $\begin{array}{l}\text { Aspirin } \\
\text { Clopidogrel } \\
\beta \text {-Blocker } \\
\text { Statin† } \\
\text { ACE inhibitorł } \\
\text { Diet modification }\end{array}$ & $\begin{array}{l}85.2 \\
38.9 \\
78.8 \\
70.2 \\
58.4 \\
64.3\end{array}$ & $\begin{array}{l}92.6 \\
63.4 \\
82.3 \\
76.0 \\
59.5 \\
73.2\end{array}$ \\
\hline $\begin{array}{l}\text { counseling } \\
\text { Smoking cessation } \\
\text { counseling }\end{array}$ & 50.1 & 64.8 \\
\hline $\begin{array}{l}\text { Cardiac rehabilitation } \\
\text { referral }\end{array}$ & 27.8 & 47.5 \\
\hline \multicolumn{3}{|c|}{ 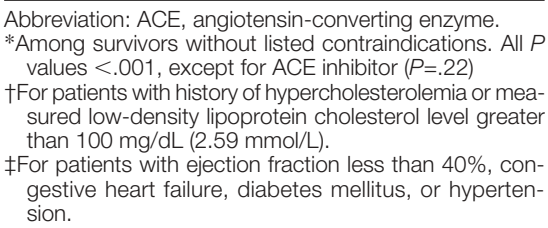 } \\
\hline
\end{tabular}

transfusion were higher. Median length of stay was also lower in patients undergoing early invasive management (3 days: 25 th, 75 th percentiles: 2,6 days) compared with patients not treated with this approach (5 days: 25 th, 75 th percentiles: 3 , 8 days) $(P<.001)$.

Sensitivity analyses (eg, excluding deaths within 24 or 48 hours) demonstrate similar findings with respect to the association between an early invasive strategy and lower mortality as seen in the overall analysis (FIGURE 1). Analyses of patient subgroups revealed similar reductions in mortality with early invasive management except for the subgroups of patients aged 75 years or older and those who were troponin-negative (Figure 1).

Patients were also stratified into low, medium, and high clinical risk based on the modified PURSUIT risk score. In all 3 risk categories, patients undergoing early invasive management had a significantly lower risk of unadjusted in-hospital mortality, although the highest-risk patients appeared to derive the greatest absolute benefit from early invasive management (FIGURE 2).

Propensity matching of patients by early invasive management status produced groups (5486 patients in each group) that were similarly matched for clinical, demographic, and hospital characteristics (all $P$ values $>.05$ except smoking) (TABLE 6). In this propensitymatched pairs sample, the frequency of in-hospital mortality was lower in patients who underwent early invasive management $(2.5 \%$ vs $3.7 \%, P<.001)$.

\begin{tabular}{|c|c|c|c|}
\hline & $\begin{array}{c}\text { No Early } \\
\text { Invasive Care, \% } \\
(n=9889)\end{array}$ & $\begin{array}{c}\text { Early } \\
\text { Invasive Care, \% } \\
(\mathrm{n}=8037)\end{array}$ & $\begin{array}{c}\text { Adjusted } \\
\text { Odds Ratio }(95 \% \mathrm{Cl}) *\end{array}$ \\
\hline Mortality & 6.2 & 2.0 & $0.63(0.52-0.77)$ \\
\hline Postadmission Ml & 3.7 & 3.1 & $0.95(0.79-1.14)$ \\
\hline Death or MI & 8.9 & 4.7 & $0.79(0.69-0.90)$ \\
\hline Cardiogenic shock & 2.3 & 2.6 & $1.88(1.47-2.40)$ \\
\hline $\mathrm{CHF}$ & 13.6 & 6.5 & $0.89(0.78-1.01)$ \\
\hline Stroke & 1.0 & 0.8 & $1.07(0.73-1.57)$ \\
\hline Any RBC transfusion & 15.3 & 13.7 & $1.25(1.12-1.38)$ \\
\hline
\end{tabular}

\section{COMMENT}

We have demonstrated that utilization of an early invasive management strategy was associated with a significantly lower risk of in-hospital mortality in high-risk patients with NSTE ACS presenting to US hospitals with both catheterization and revascularization capabilities, although less than half of patients were managed with this approach. Patients undergoing early invasive management were younger and more commonly cared for by cardiologists, whereas older patients with comorbidities were less likely to undergo early invasive management. The relationship between early invasive management and improved guidelines adherence for acute and discharge medication use indicates that appropriate overall guidelines-based care is more commonly delivered to patients treated with an early invasive strategy.

The updated ACC/AHA guidelines recommend an early invasive strategy for NSTE ACS patients presenting with high-risk features including ischemic electrocardiographic changes, elevated troponin levels, new CHF symptoms, left ventricular dysfunction, prior PCI within 6 months, prior CABG, and hemodynamic instability. ${ }^{9}$ Whereas ischemic electrocardiographic changes, positive cardiac markers, and prior PCI were significant predictors of early invasive management in this analysis, patients with prior CABG, prior or current $\mathrm{CHF}$, and faster presenting heart rate were significantly less likely to undergo early invasive management. These findings may be explained by the strong association of cardiology care with early invasive management, as cardiologists have been shown to provide appropriate evidence-based care more commonly than general practitioners, but also suggest that features that may be perceived to increase the risks associated with invasive procedures (renal insufficiency, advanced age, CHF) also strongly influence decisions regarding use of invasive cardiac procedures. ${ }^{18,19}$ Factors influencing physician decision making are difficult to 
ascertain, but it appears that younger, healthier patients selectively undergo early invasive management in the United States, while older patients with more comorbidities are treated conservatively, even though these patients have a higher risk of mortality and may derive greater absolute benefit from aggressive management.

Disparities in the utilization of invasive cardiac procedures demonstrated in this analysis appear to be related to longstanding treatment biases. A previous registry of NSTE ACS patients from the last decade showed that elderly patients, women, and minorities were significantly less likely to be referred for cardiac catheterization during the initial hospitalization. ${ }^{20}$ Other studies have also demonstrated similar referral biases and underutilization of cardiac catheterization in the elderly, women, and minorities. ${ }^{21,22}$ Even though recent studies have shown significant reductions in adverse clinical outcomes with early invasive management and revascularization in patients with NSTE ACS who are at highest risk for adverse outcomes, the elderly, and those with renal insufficiency, we have shown high-risk features, advanced age, and renal insufficiency are negative predictors of early invasive management. ${ }^{23-27}$ Thus, preexisting treatment biases present significant obstacles that must be overcome to improve the outcomes of undertreated subgroups of patients with NSTE ACS who are unlikely to be managed aggressively in current practice.

Notwithstanding biases in the use of invasive procedures, the greater use of acute evidence-based medical therapies in patients receiving early invasive management suggests that overall guidelines adherence tends to mirror trends in procedural utilization. Antiplatelet therapies, including clopidogrel and intravenous Gp IIb/IIIa inhibitors, have been shown to reduce the composite of death or MI in patients with NSTE ACS, and these therapies were used much more commonly in patients undergoing early invasive management. ${ }^{1,4,28,29}$ Furthermore, patients undergoing early
Figure 1. Sensitivity and Subgroup Analyses for Adjusted In-Hospital Mortality by Utilization of an Early Invasive Management Strategy $(\mathrm{N}=17926)$

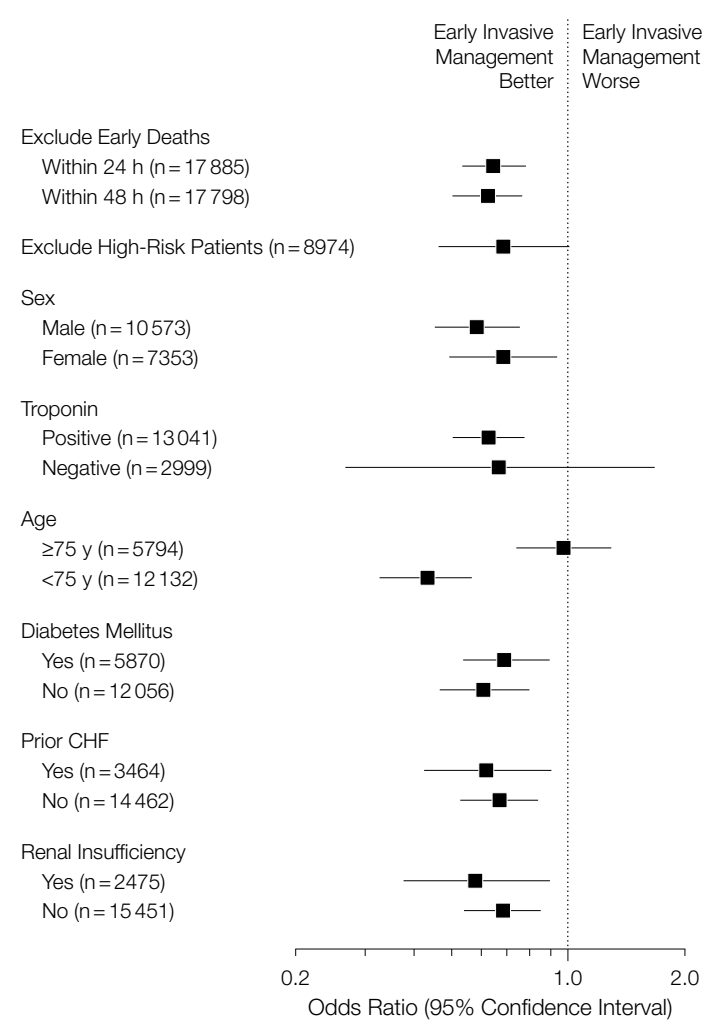

High-risk is defined as age older than 80 years, chronic renal insufficiency, prior congestive heart failure (CHF), prior stroke, signs of CHF at presentation, or presenting systolic blood pressure less than $90 \mathrm{~mm} \mathrm{Hg}$. There are missing data for troponin positive and negative as some patients qualified for entry based on creatine kinase-MB or electrocardiographic criteria and did not have a troponin measurement.

invasive management also more commonly received other acute and discharge therapies designated as Class IA or IB recommendations by the ACC/ AHA guidelines. ${ }^{9,13}$ While the differential impact of multiple medical therapies and revascularization on clinical outcomes in an observational analysis is difficult to elucidate and highly confounded by the periprocedural use of medications (heparin, clopidogrel, Gp IIb/IIIa inhibitors) in patients undergoing PCI, these results suggest that evidence-based medical therapies are underutilized in higher-risk patients in the same fashion as early invasive management strategies.

Several contemporary randomized clinical trials have shown clinical benefits with a strategy of early invasive management and revascularization, but early invasive management was asso-
Figure 2. Unadjusted In-Hospital Mortality Rates by Early Catheterization Among Risk Categories Determined From Presenting Clinical Characteristics

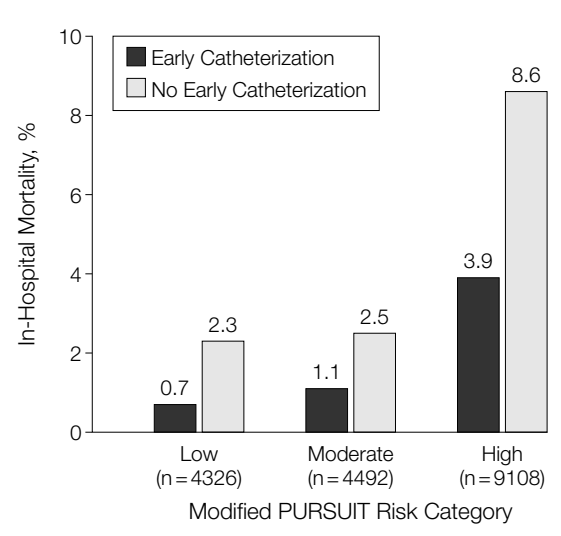

$P$ values for comparisons within each risk group were $<.001$. PURSUIT indicates the Platelet glycoprotein IIb/IIla in Unstable angina: Receptor Suppression Using Integrilin (eptifibatide) Therapy trial. 
ciated with a significant survival benefit only in the FRISC II trial. ${ }^{6,8}$ Older Wave Infarction Strategies in Hospital (VANQWISH) did not find a benefit with an early invasive strategy, but techtrials such as Veterans Affairs Non-Q-

nological advances such as intracoronary stents and better adjuvant pharmacotherapies may explain the difference between VANQWISH and trials such as TACTICS-TIMI 18 or FRISC II and perhaps the current find-

Table 6. Baseline Characteristics Comparisons on Propensity-Matched Pairs by No Early Catheterization vs Early Catheterization*

\begin{tabular}{|c|c|c|c|}
\hline Characteristic & $\begin{array}{c}\text { No Early } \\
\text { Invasive Care } \\
(\mathrm{N}=5486)\end{array}$ & $\begin{array}{c}\text { Early } \\
\text { Invasive Care } \\
(\mathrm{N}=5486)\end{array}$ & $\begin{array}{c}P \\
\text { Value }\end{array}$ \\
\hline \multicolumn{4}{|l|}{ Demographics } \\
\hline Age, median (IQR), y & $66(55-77)$ & $66(56-76)$ & .27 \\
\hline Female sex & $2189(39.90)$ & 2173 (39.61) & .76 \\
\hline BMI, median (IQR) & $28(25-32)$ & $28(25-32)$ & .59 \\
\hline White race & $4249(77.45)$ & $4290(78.20)$ & .35 \\
\hline \multicolumn{2}{|l|}{ Insurance status } & $2578(46.99)$ & .08 \\
\hline Medicaid/Medicare & $2530(46.12)$ & $2479(45.19)$ & .33 \\
\hline Self/none & $468(8.53)$ & $429(7.82)$ & .17 \\
\hline \multicolumn{3}{|l|}{ Risk factors } & .66 \\
\hline Hypertension & $3816(69.56)$ & $3758(68.50)$ & .23 \\
\hline Diabetes mellitus & $1742(31.75)$ & $1721(31.37)$ & .67 \\
\hline Current/recent smoker & $1502(27.38)$ & 1609 (29.33) & .02 \\
\hline Hypercholesterolemia & $2676(48.78)$ & $2634(48.01)$ & .42 \\
\hline \multicolumn{4}{|l|}{ Medical history } \\
\hline Prior PCl & $1377(25.10)$ & $1344(24.50)$ & .47 \\
\hline Prior CABG & $1171(21.35)$ & $1156(21.07)$ & .73 \\
\hline Prior CHF & $630(11.48)$ & $667(12.16)$ & .27 \\
\hline Prior stroke & $464(8.46)$ & 467 (8.51) & .92 \\
\hline Renal insufficiency† & $478(8.71)$ & $499(9.10)$ & .48 \\
\hline \multicolumn{4}{|l|}{ Presenting characteristics } \\
\hline$\overline{\mathrm{SBP}}$, median (IQR), mm Hg & $147(129-168)$ & $147(128-167)$ & .49 \\
\hline ST depression & $2233(40.70)$ & 2175 (39.65) & .26 \\
\hline Transient ST elevation & $554(10.10)$ & $593(10.81)$ & .22 \\
\hline Positive cardiac markers & $4648(84.72)$ & 4661 (84.96) & .73 \\
\hline CHF at presentation & $890(16.22)$ & $895(16.31)$ & .89 \\
\hline \multicolumn{3}{|l|}{ Hospital characteristics } & .96 \\
\hline Hospital beds, median (IQR), No. & $426(291-552)$ & $428(291-552)$ & .08 \\
\hline COTH hospital & $1846(33.65)$ & $1799(32.79)$ & .34 \\
\hline \multicolumn{4}{|l|}{ Region } \\
\hline South & $1952(35.58)$ & $1933(35.24)$ & \multirow{3}{*}{.82} \\
\hline West & $542(9.88)$ & $559(10.19)$ & \\
\hline Midwest & $2027(36.95)$ & $2009(36.62)$ & \\
\hline Cardiology careł & 3346 (60.99) & $3351(61.08)$ & .92 \\
\hline Off-hours presentation§ & 3051 (55.61) & $3094(56.40)$ & .41 \\
\hline \multicolumn{4}{|c|}{$\begin{array}{l}\text { Abbreviations: BMI, body mass index, calculated as weight in kilograms divided by the square of height in meters; } \\
\text { CABG, coronary artery bypass graft; CAD, coronary artery disease; CHF, congestive heart failure; COTH, Council of } \\
\text { Teaching Hospitals; HMO, health maintenance organization; IQR, interquartile range; PCl, percutaneous coronary } \\
\text { intervention; SBP, systolic blood pressure. } \\
\text { *Data are presented as number and percentage unless otherwise indicated. } \\
\text { †Defined as creatinine level greater than } 2.0 \mathrm{mg} / \mathrm{dL} \text { ( }(176.8 \mu \mathrm{mol} / \mathrm{L}) \text {, calculated creatinine clearance less than } 30 \mathrm{~mL} / \\
\text { min (0.5 mL/s), or need for chronic renal dialysis. } \\
\text { fAdmitted to a primary cardiology service. } \\
\text { \$Presentation from } 5 \text { PM to } 7 \text { AM on weekdays and anytime on weekends. }\end{array}$} \\
\hline
\end{tabular}

ing from CRUSADE. ${ }^{23,24,30}$ Whereas the mortality benefit with early invasive management in FRISC II was not apparent until after 3 months, ${ }^{8}$ the survival advantage demonstrated in CRUSADE occurred during the initial hospitalization, but the higher rate of in-hospital mortality in CRUSADE compared with clinical trials may have led to a greater degree of absolute benefit. However, the relationship of lower mortality with early invasive management in CRUSADE may have been somewhat overestimated given the significant selection biases demonstrated in the use of early invasive management. Finally, there is also a greater separation of strategies in this analysis from CRUSADE compared with randomized trials (in which patients assigned to a conservative approach would still undergo catheterization and revascularization for recurrent or inducible ischemia).

This early CRUSADE experience clearly documents a gap between the evidence-based ACC/AHA guidelines recommendations and actual clinical practice. Indeed, lack of compliance with guidelines appears to be prevalent across a variety of medical conditions. ${ }^{31}$ In the case of application of an early invasive strategy, perhaps part of the reluctance of physicians to apply the guidelines is due to concerns that the guidelines may not be valid in certain subsets of highrisk patients encountered in daily clinical practice ${ }^{32}$ but not enrolled or underrepresented in clinical trials, such as women or elderly patients or those with heart or renal failure. However, observational analyses such as this one may provide some degree of reassurance of the applicability of randomized trial data to patients treated in routine practice. ${ }^{25}$ Another possible reason for the disconnect between guidelines recommendations and actual practice may have to do with inadequacies in the way that care for ACS is delivered and it may be best approached as health care systems' deficiencies rather than as an individual practitioner's shortcoming. ${ }^{33}$ For example, regionalization of care for NSTE ACS at "heart attack" centers, in a man- 
ner analogous to trauma centers, has been proposed as a means to improve care, which would certainly lead to an appropriate increase in use of an early invasive strategy, especially if community hospitals were specifically directed to transfer rapidly high-risk NSTE ACS patients for early catheterization, but significant political obstacles must be overcome before this type of system could be implemented. ${ }^{34}$

As a dynamic quality improvement initiative, CRUSADE will attempt to modify practice via continuous feedback to participating institutions regarding benchmarked adherence to the ACC/AHA guidelines, implementation of quality improvement interventions such as standardized admission orders, and other educational efforts. Within this context, the slight upward trends in the use of early invasive management during the study period are encouraging. The CRUSADE initiative will complement other ongoing efforts to improve cardiovascular care through adherence to established guidelines, such as the AHA's Get with the Guidelines program and the ACC's Guidelines Applied in Practice Initiative. ${ }^{35,36}$

\section{Limitations}

There are certain limitations in this retrospective, observational analysis. First, the revisions to the ACC/AHA guidelines that gave a Class IA recommendation for early invasive management were first released in March 2002 and were not published until October 2002 (spanning the end of the study period), so this study may not have been long enough to evaluate the full effect of the updated guidelines on practice patterns. ${ }^{9}$ However, the original 2000 ACC/AHA guidelines for NSTE ACS gave a Class IB recommendation for early invasive management, so presumably this approach should have been considered in the same fashion as other generally accepted Class IB acute care recommendations from the 2000 guidelines, such as $\beta$-blockers and heparin. ${ }^{13}$ Second, these data may represent a "best-case" scenario, as sites participate in CRUSADE on a volun- tary basis and may have had an interest in quality improvement and therefore may have been more likely to adhere to practice guidelines than other US hospitals. Third, cardiology care was the strongest predictor of early invasive management, but this variable only described the primary admitting service and did not account for the impact of cardiology consultation on treatment decisions. Fourth, the decision to perform cardiac catheterization was not randomized but was at the discretion of the treating physician. Unmeasured confounding variables may have accounted for some of the differences in mortality, although propensity matching and sensitivity analyses were performed to attempt to address this limitation. Fifth, there may have been appropriate contraindications to cardiac catheterization that were not collected, unlike the situation with medications where contraindications were documented and were used to determine medication usage rates in "ideal" patients. Sixth, the impact of revascularization procedures following catheterization on clinical outcomes was not assessed in this analysis, so the impact of an early invasive management strategy was not fully characterized. Seventh, because long-term outcomes are not followed in CRUSADE, the longterm outcomes of early invasive management were not determined. Finally, we analyzed treatment only at hospitals with revascularization capabilities, but the underutilization of early invasive management may be even greater for patients who initially present to community hospitals without catheterization or revascularization facilities and exclusion of these patients from the analysis represents a selection bias.

\section{Conclusions}

An early invasive management strategy is associated with lower inhospital mortality in NSTE ACS patients treated in routine clinical practice. This strategy, already validated in randomized clinical trials, is utilized in a minority of high-risk NSTE ACS pa- tients and appears to be preferentially reserved for younger patients without comorbidities who were cared for by cardiologists. Therefore, quality improvement efforts should focus on educational interventions that target noncardiologists involved in the care of NSTE ACS patients and on improving the appropriate use of invasive cardiac procedures and other guidelines recommendations for all high-risk patients.

Author Contributions: Dr Bhatt had full access to all of the data in the study and takes responsibility for the integrity of the data and the accuracy of the data analysis.

Study concept and design: Bhatt, Roe, Li, Harrington, Berger, Cannon, Pollack, Gibler.

Acquisition of data: Bhatt, Roe, Peterson, Cannon, Cohen, Kleiman, Peacock, Pollack, Gibler.

Analysis and interpretation of data: Bhatt, Roe, Peterson, Li, Chen, Harrington, Greenbaum, Berger, Cannon, Cohen, Gibson, Saucedo, Hochman, Boden, Brindis, Peacock, Smith, Pollack, Gibler, Ohman. Drafting of the manuscript: Bhatt, Roe, Li, Peacock, Pollack.

Critical revision of the manuscript for important intellectual content: Bhatt, Roe, Peterson, Chen, Harrington, Greenbaum, Berger, Cannon, Cohen, Gibson, Saucedo, Kleiman, Hochman, Boden, Brindis, Peacock, Smith, Pollack, Gibler, Ohman.

Statistical analysis: Bhatt, Li, Chen, Cannon.

Obtained funding: Peterson, Harrington, Pollack, Gibler.

Administrative, technical, or material support: Roe, Harrington, Hochman, Boden, Peacock.

Study supervision: Roe, Peterson, Gibson, Ohman. Executive Committee Oversight: Brindis.

Funding/Support: CRUSADE is funded by Millennium Pharmaceuticals Inc and Schering Corporation. Bristol-Myers Squibb/Sanofi Pharmaceuticals Partnership provides an unrestricted grant in support of the program. Duke Clinical Research Institute owns the CRUSADE database and independently manages data collection, data analysis, and data interpretation without sponsor oversight.

Role of the Sponsors: All manuscripts in CRUSADE are prepared by independent authors who are not governed by the funding sponsors and are reviewed by an academic publications committee before submission. The funding sponsor has a representative (Theresa Palabrica, MD, Millennium Pharmaceuticals Inc) on the committee who provides input into manuscript design and content, but does not have authority to change any aspect of the manuscript.

\section{REFERENCES}

1. Bhatt DL, Topol EJ. Current role of platelet glycoprotein Ilb/IIla inhibitors in acute coronary syndromes. JAMA. 2000;284:1549-1558.

2. Cohen M, Demers C, Gurfinkel EP, et al; Efficacy and Safety of Subcutaneous Enoxaparin in Non-QWave Coronary Events Study Group. A comparison of low-molecular-weight heparin with unfractionated heparin for unstable coronary artery disease. N Engl J Med. 1997;337:447-452.

3. Antman EM, McCabe CH, Gurfinkel EP, et al. Enoxaparin prevents death and cardiac ischemic events in unstable angina/non-Q-wave myocardial infarction: results of the Thrombolysis In Myocardial Infarction (TIMI) 11B trial. Circulation. 1999;100:1593-1601. 
4. Yusuf S, Zhao F, Mehta SR, Chrolavicius S, Tognoni G, Fox KK. Effects of clopidogrel in addition to aspirin in patients with acute coronary syndromes without ST-segment elevation. N Eng/J Med. 2001;345: 494-502.

5. Cho L, Bhatt DL, Marso SP, et al. An invasive strategy is associated with decreased mortality in patients with unstable angina and non-ST-elevation myocardial infarction: GUSTO Ilb trial. Am J Med. 2003;114: 106-111.

6. Cannon CP, Weintraub WS, Demopoulos LA, et al. Comparison of early invasive and conservative strategies in patients with unstable coronary syndromes treated with the glycoprotein IIb/IIla inhibitor tirofiban. N Engl J Med. 2001;344:1879-1887.

7. FRagmin and Fast Revascularisation during InStability in Coronary artery disease Investigators. Invasive compared with non-invasive treatment in unstable coronary-artery disease: FRISC II prospective randomised multicentre study Lancet 1999-354:708-715.

8. Wallentin L, Lagerqvist B, Husted S, Kontny F, Stahle E, Swahn E; FRISC II Investigators. Outcome at 1 year after an invasive compared with a non-invasive strategy in unstable coronary-artery disease: the FRISC II invasive randomised trial. Lancet. 2000;356:9-16.

9. Braunwald E, Antman EM, Beasley JW, et al. ACC/ AHA 2002 guideline update for the management of patients with unstable angina and non-ST-segment elevation myocardial infarction-summary article: a report of the American College of Cardiology/ American Heart Association task force on practice guidelines (Committee on the Management of $\mathrm{Pa}$ tients With Unstable Angina). J Am Coll Cardiol. 2002; 40:1366-1374.

10. Pollack CV Jr, Roe MT, Peterson ED. 2002 update to the ACC/AHA guidelines for the management of patients with unstable angina and non-STsegment elevation myocardial infarction: implications for emergency department practice. Ann Emerg Med. 2003;41:355-369.

11. Bassand JP. Improving the quality and dissemination of guidelines: the quest for the Holy Grail. Eur Heart J. 2000;21:1289-1290

12. Hoekstra JW, Pollack CV Jr, Roe MT, et al. Improving the care of patients with non-ST-elevation acute coronary syndromes in the emergency department: the CRUSADE initiative. Acad Emerg Med. 2002; 9:1146-1155.

13. Braunwald E, Antman EM, Beasley JW, et al. ACC/ $\mathrm{AHA}$ guidelines for the management of patients with unstable angina and non-ST-segment elevation myocardial infarction: a report of the American College of Cardiology/American Heart Association Task Force on
Practice Guidelines (Committee on the Management of Patients with Unstable Angina). J Am Coll Cardiol. 2000;36:970-1062.

14. Liang KY, Zeger SL. Longitudinal data analysis using generalized linear models. Biometrika. 1986;73:1322.

15. Boersma E, Pieper KS, Steyerberg EW, et al; The PURSUIT Investigators. Predictors of outcome in patients with acute coronary syndromes without persistent ST-segment elevation: results from an international trial of 9461 patients. Circulation. 2000;101: 2557-2567.

16. Rosenbaum PR, Rubin DB. Reducing bias in observational studies using subclassification on the propensity score. J Am Stat Assoc. 1984;79:516-524.

17. Parsons LS. Reducing bias in a propensity score matched-pair sample using Greedy matching techniques. Proceedings of the 26th Annual SAS Users Group International Conference, Cary, NC: SAS Institute Inc, 2001. Available at: http://www2.sas com/proceedings/sugi26/p214-26.pdf. Accessibility verified October 7, 2004

18. Jollis JG, DeLong ER, Peterson ED, et al Outcome of acute myocardial infarction according to the specialty of the admitting physician. N Engl J Med. 1996;335:1880-1887.

19. Chen J, Radford MJ, Wang Y, Krumholz HM. Care and outcomes of elderly patients with acute myocardial infarction by physician specialty: the effects of comorbidity and functional limitations. Am J Med. 2000; 108:460-469.

20. Sharis PJ, Cannon CP, Rogers WJ, et al. Predictors of mortality, coronary angiography, and revascularization in unstable angina pectoris and acute non-ST elevation myocardial infarction (The TIMI III Registry). Am J Cardiol. 2002;90:1154-1156.

21. Schulman KA, Berlin JA, Harless W, et al. The effect of race and sex on physicians' recommendations for cardiac catheterization. N Eng/ J Med. 1999;340:618626.

22. Petersen LA, Normand ST, Leape LL, McNeil BJ. Regionalization and the underuse of angiography in the Veterans Affairs health care system as compared with a fee-for-service system. N Engl J Med. 2003;348: 2209-2217.

23. Sabatine MS, Morrow DA, Guigliano RP, et al. Implications of upstream glycoprotein IIb/IIla inhibition and coronary artery stenting in the invasive management of unstable angina/non-ST-elevation myocardial infarction. Circulation. 2004;109:874-880 24. Bavry AA, Kumbhani DJ, Quiroz R, Ramchandani R, Kenchaiah S, Antman EM. Invasive therapy along with glycoprotein Ilb/IIla inhibitors and intracoronary stents improves survival in non-ST-segment elevation acute coronary syndromes: a meta-analysis and review of the literature. Am J Cardiol. 2004;93:830-835 25. Bach RG, Cannon CP, WeintraubWS, etal. The effect of routine, early invasive management on outcome for elderly patients with non-ST-elevation acute coronary syndromes. Ann Intern Med. 2004;141:186-195.

26. Januzzi JL, Cannon CP, DiBattiste PM, Murphy $S$, Weintraub W, Braunwald E. Effects of renal insufficiency on early invasive management in patients with acute coronary syndromes (the TACTICS-TIMI 18 Trial). Am J Cardiol. 2002:90:1246-1249.

27. Keeley EC, Kadakia R, Soman S, Borzak S, Mc Cullough PA. Analysis of long-term survival after re vascularization in patients with chronic kidney disease presenting with acute coronary syndromes. Am J Cardiol. 2003;92:509-551.

28. The PURSUIT Trial Investigators. Inhibition of platelet glycoprotein IIb/IIla with eptifibatide in patients with acute coronary syndromes. N Eng/ J Med. 1998;339: 436-443.

29. The PRISM-PLUS Investigators. Inhibition of the platelet glycoprotein Ilb/IIla receptor with tirofiban in unstable angina and non-Q-wave myocardial infarction. N Engl J Med. 1998;338:1488-1497.

30. Boden WE, O'Rourke RA, Crawford $M H$, et al Veterans Affairs Non-Q-Wave Infarction Strategies in Hospital (VANQWISH) Trial Investigators. Out comes in patients with acute non-Q-wave myocar dial infarction randomly assigned to an invasive as compared with a conservative management strategy. N Engl J Med. 1998;338:1785-1792.

31. McGlynn EA, Asch SM, Adams J, et al. The quality of health care delivered to adults in the United States. N Eng/ J Med. 2003;348:2635-2645.

32. Garg PP, Landrum MB, Normand SL, et al. Understanding individual and small area variation in the underuse of coronary angiography following acute myocardial infarction. Med Care. 2002;40:614-626. 33. Leape LL, Berwick DM, Bates DW. What practices will most improve safety? evidence-based medicine meets patient safety. JAMA. 2002;288:501-507 34. Topol EJ, Kereiakes DJ. Regionalization of care for acute ischemic heart disease: a call for specialized centers. Circulation. 2003:107:1463-1466.

35. Denton TA, Fonarow GC, LaBresh KA, Trento A Secondary prevention after coronary bypass: the American Heart Association "Get with the Guidelines" program. Ann Thorac Surg. 2003;75:758-760.

36. Mehta RH, Montoye CK, Gallogly M, et al. Improving quality of care for acute myocardial infarction: the Guidelines Applied in Practice (GAP) Initiative. JAMA. 2002;287:1269-1276. 